Since the War, the Hydrometeorological Service has been greatly expanded further. Separate specialist branches have been set up for particular branches of the econony. Emphasis is placed on activities of special importance to the economy of the Union, for example, civil aviation, the hydrology of rivers and watersheds, agricultural meteorology. Nevertheless, the confession is made that the rate of improvement in the accuracy of the forecasts has not really been adequate to satisfy its needs.

Dr. Zolotuhin, however, makes the point that it is the level of scientific research which determines the quality of the service, and there are now a consider. able number of meteorological, hydrological and oceanographical research institutions in the U.S.S.R., and the Hydrometeorological Service also has a number of specialist educational establishments for training its staff and potential staff.

From the complete decline of 1921 , the past forty years have clearly been years of major expansion; an expansion which indicates the importance attached by the U.S.S.R. to the sciences of meteorology and hydrology. Indeed, with its 29 local and republic directorates and its 20,000 observing points, embracing one-sixth of the Earth's land surface, the Soviet Hydrometeorological Service must now surely be about the largest in the world.

R. F. ZOBEL

\title{
POPULATION TRENDS IN THE U.S.S.R. AND THE UNITED STATES
}

$\mathrm{N}$ terms of population, the Soviet Union and the 1 United States are the third and fourth largest nations in the world. Their combined population of approximately 402 million is close to the population of India, but only slightly more than half that of China. The two nations are alike in many demographic respects, A recent survey entitled "PopulationTrends in the U.S.S.R.", issued by the Population Reference Bureau, Inc., compares the various population trends in the U.S.S.R. with those in the United States*.

In 1959, the Soviet census counted 209 million people. The birth-rate was 25 , the death-rate $7 \cdot 6$ per thousand. In 1959, the United States population. was 176 million, and the birth-rate $24 \cdot 1$ and the death-rate $9 \cdot 4$ per thousand. The age-specific deathrates in the U.S.S.R. were higher than those of the United States below age forty, and lower above that age. In both countries, the populations are made up of many ethnic groups; illiteracy is virtually non. existent, and great numbers of people are receiving more education. Only 1.5 per cent of Russians aged 9-49 were reported by the census to be illiterate, but there are urban-rural differences at every school-

* Population Reference Bureau, Inc. Population Bulletin, Vol. 17, No. 6 (October 1961): Population Trends in the U.S.S.R. Pp. v+76. level. The educational pattern is very different in the two countries.

Migratory trends are similar. With the growth of industrialization, the people of both nations have been on the move, mainly from the agricultural areas to the urban areas. The force which motivates this migration is mainly the desire for advancement.

In 1926,82 per cent of the population in the U.S.S.R. lived in rural areas and 18 per cent lived in cities. By 1959 the proportion had changed to 52 per cent rural and 48 per cent urban. Russians have been moving east in response to a Governmentplanned effort to colonize the 'new lands' where industrial complexes have been established.

In contrast, Americans have been going west and mainly into urban areas in a wholly unplanned, casual manner because they desire to live and work there. In 1900,60 per cent of the population of the United States was rural and 40 per cent was urban. By 1960, the proportion had changed, 37 per cent being rural and 63 per cent urban.

There is a vast difference in the kinds of occupation in the two countries. In 1959 , almost 39 per cent of the total labour force in the U.S.S.R. was engaged in agriculture. In 1960 less than 9 per cent of the labour force in the United States was so employed.

\section{NEW SYNTHETIC DETERGENTS}

\begin{abstract}
A LTHOUGH the biologically 'soft' detergent which has been developed by the manufacturers, and has been widely distributed in the south of England, has eased the difficulties which have been caused by the discharge of detergent residues to surface waters, the new material does not afford a complete solution to the problems arising from the widespread use of synthetic detergents, and further improvement of this material or the development of new types of surface-active materials is necessary. This is the gist of the Fourth Progress Report of the Standing Technical Committeo on Synthetic Detergents *. The new 'soft' detergent, originally supplied to the Luton area, has now been distributed to a large part of southern England, and increased removal of detergents at sewage treatment plants has been observed in many distriets. No similar change has

* Ministry of Housing and Local Government. Fourth Progress Report of the Standing Technical Committee on Synthetic Detergents. Pp. 19. (London: H.M.S.O., 1961.) 18. 6d. net.
\end{abstract}

taken place in the north, where the type of detergent on sale has not been altered.

One of the difficulties encountered in experimental work on the breakdown of synthetic detergents is the lack of analytical techniques which can be used to study the breakdown products. The analytical methods used are specific for molecules of a given range of size and structure, and it is possible that during sewage treatment some molecules may be only partly degraded or otherwise changed in structure, and may then be undetected in the effluent. It is therefore emphasized in the report that figures given for percentage removal do not necessarily imply that the material has been fully degraded. An extensive programme to be undertaken by various members of the Committee will include investigations of the biological breakdown of single substances, in order to throw light on this part of the problem.

Nora H. JoHNSON 